\title{
Some Aspects of Forensic Identification
}

\author{
Lucia Cerasela Balan \\ Faculty of Economic Sciences and Public Administration, Law specialization from Suceava, Romania \\ Master in Criminal Sciences at "Dimitrie Cantemir" Christian University of Bucharest, Romania,_Lucya_9212@yahoo.com
}

\begin{abstract}
Forensic identification is a very important factor in the investigation of both civil and criminal investigations. The object of forensic identification is the whole of the objects, phenomena, qualities, time and space intervals, the physical attributes or psychic actions of the person. Almost all cases are directly linked to the person, and information about the appearance or appearance of a person is among the most important. Information about age, gender, ethnicity is provided by the unique and almost unique look that each person is endowed with. Available evidence about a person's physical appearance can always be associated with functional features such as voice, hair color, mimics, etc. The essential content of probation with the help of forensic identification is the detection, detachment of the object or person involved from an indeterminate totality of objects or potential persons. Of great importance are both the clothes and the personal objects that give a complete picture and help identify the person. Specialized persons have the duty to perform the identification activity.
\end{abstract}

KEYWORDS: identification, legal activity, forensics, object, person

\section{Introduction}

The purpose of Forensic research is to support investigative processes and discover traces in raw materials from which there is the possibility of building events and activities.

Personal identity, corroborated with evidence from various sources of evidence, has led to the development of methods and procedural means that help to solve cases in the field of forensic research.

The problem of identifying people was born with the appearance of man on the earth, since then a distinction has been made between people, and later this necessity has acquired a legal character. This was due to the fact that society began to know the elements harming social harmony, which had to be mastered, isolated and punished in relation to the gravity of the committed deeds (Nechita 2009, 14). Judicial identification is an indissoluble activity linked to the fulfillment of the act of justice and the prevention of antisocial phenomena. The detection of offenders, the identification of recidivists, the proving of criminal offenses and guilt, the determination of the circumstances in which they occurred, and other situations, including those relating to the settlement of civil disputes, necessarily require the identification of persons and objects (Ionescu and Sandu 2011, IX).

The main way to reach judicial identification is Forensic Identification. It appears not only in the middle but as a premise of judicial identification. The correct understanding of Forensic Identification and its application in practice is fundamental to the act of justice (Buzatu 2013, 20).

The process of identifying individuals, objects or even phenomena related to the illicit deed through forensic methods in order to establish veracity in the judicial process is the whole of the idea of forensic identification. The process of identification is based on the possibility of recognizing the objects of the material world by fixing in our thinking process their characteristics and by the relative change for at least a period of time (Ionescu and Sandu 2011, 172).

The criminalist has the duty to go with the identification to the level of an individual or object and not to remain at the generic level of the group of objects or the category of individuals according to the extent to which the means of examination and the methodology available at that time allow for individual identification. Finding the membership of the group to which the identification is part is not sufficient, the process having to proceed by means of comparison as a single object that created the trace from which it departs.

Regardless of who has been made the identification and the procedural form in which it has materialized, the connection between the deed and the person or the identified object rests solely with the judicial body. By corroborating the identity conclusion with the data provided by other evidence, forensic identification becomes judicial (Buzatu 2013, 21). 
The relationship between them could be defined as a part-to-whole report, where the part is forensic identification and the entire judicial identification. This stems from their succession (the first precedent of the second), from the position it occupies in the probation (the first is subordinated to the second) and, above all, from the content and extent of each (Ionescu and Sandu 2011, IX).

The generalization of jurisprudence and expertise has led to the development of a theory of identification in the field of criminology, which is also useful for specialists and law enforcement. For the first one is a methodology and a working tool, for others a correct interpretation guide for scientifically determined data (Idem). In the literature (Ionescu 2007, 159), forensic identification has been defined as the establishment by technical-scientific means of the identity of a being or an object related to the crime in question.

\section{The subject of Forensic Identification}

A material object of forensic identification can be any person, being or thing, any element of the material world that takes place in space and time, capable of being identified by the fingerprints created during the crime. The object of identification is a precise fact through the causal relationship itself with the deed investigated.

In a general sense, the object of forensic identification is constituted by the whole of the objects, phenomena, qualities, time and space intervals, physical attributes or mental actions of the individual. In a narrow sense, the subject of forensic identification is made up of the solid elements of the material world, with relatively constant volumes and characteristics.

Forensic identity is the process of determining the identity of a person, object or beings all in a causal relationship with the act criminalized by criminal law (Stancu 2010, 170). At the same time, this process has a unitary character, the identification being realized gradually, starting from general to particular. Throughout this process, all the specific attributes of objects, individuals or animals go through a selection stage that specifies the genre, group, species, type, model, etc.

\section{The scientific premises of forensic identification}

\section{Individuality}

The scientific basis of identification is individuality, unrepeatability, where the possibility of separating one object from another or similar. Individuality is given the initial attributes of the object and those acquired later, through use and exploitation (Buzatu 2013, 22).

\section{Relative stability}

Objects and beings undergo changes under the influence of internal and external factors. Continuing the movement and transformation of the material world does not contradict the property of an object to be individual (Ionescu 2007, 160-161).

For certain time intervals, for example during the investigation, identification remains possible when changes are not essential. In this context, the individual appears to be relatively stable.

Apart from natural factors, there are also cases of artificial modification: writing disguise, axle blade failure, fingers, traces, etc.

\section{Reflectivity}

The reflection of interest in the identification process consists in the change by which on or in an object there is a change of substance, the printing of the image of another object or some of its attributes (Buzatu 2013, 22).

In this situation the creative object will be the one reflected and the inviting object the one that reflects.

\section{Establishment of gender or generic identification}

Establishing gender is at the forefront of forensic identification in the event of a positive consequence, continuing analysis until identity is established. The specification of generic membership is dependent on some rules established by the forensic practice.

Among these, we can exemplify the following: 
1. In order to identify the unknown person, the information on the description of the obvious features from the first visual contact without establishing direct contact with it, ethnicity, state belonging must be determined.

2. If the determination of the person's belonging is not possible, it is subject to examination in a given gender. The forensic specialist must make a pronouncement on both gender and possible subclassifications.

3. If it is necessary to specify the belonging of several persons to the same genre, the one responsible for this procedure is the forensic expertise that can find that objects are the same, without specifying gender (Bercheşan 2007, 53).

4. If a forensic specialist is provided with a follower, the determination of gender must be made in relation to reflecting the external structure of the contact surface (Ionescu and Sandu 2011, 11).

5. In order to be able to establish gender identity, the characteristics must be quantitative enough.

6. The differences and the heterogeneity of the compared objects or substances have a great importance in determining the generic membership.

7. Emphasizing the essential differences results in the denial of gender in the conclusion and the identity

8. The more the group of the analyzed object is more restrained, the greater the likelihood of identity and the higher the number of common elements, the higher the difficulty and the chances of identifying the person or object are lower.

9. In order to be able to establish distinctive criteria, differences must exist, that is, be real and not artificially created by accidental circumstances (Bercheşan 2006, 53-55).

\section{The Stages of Forensic Identification}

For the identification of forensics, we must go through certain stages:

\section{Preliminary examination}

The preliminary examination is the first step of the examination itself the preliminary examination is a preparatory phase.

First of all, the forensic specialist must focus on researching the tasks resulting from scientific research or expertise. It must distribute the tasks in an organized manner to the team they work with. Second, the forensic specialist must organize the conduct of scientific research or expertise.

\section{Intrinsic examination}

This phase of the intrinsic examination consists in the interpretation of the general and personal characteristics of each object, in order to establish the identity.

As a rule, this stage starts with a litigation and continues with the object to be identified following the comparison route (Bercheşan 2000, 61). This step is based on the analysis, designed to determine the characteristics of the objects either in the following or the object in its entirety as well as in certain parts. Thus, the analysis of characteristics and other defining elements implies observation (Bercheşan 2000, 62).

\section{Comparative examination}

At this stage, the comparison is the fundamental method. It is accomplished by confronting two or more persons, beings or objects to appreciate the similarities and differences between them and the demonstration of identity or identity.

\section{Formulate the conclusion}

The assessment of the consequences of the comparative research and the interpretation thereof undoubtedly establishes the greatest responsibility of the whole examination. As is also evidenced by the literature (Bercheşan 2000, 65), this phase has the role of assessing whether the sum of the constant characteristics is irreparable and unique.

The conclusion should only bear on the issues in which the expert is competent, must be precise and accessible, explicit, understandable for a non-specialist (Buzatu 2013, 25).

In relation to the degree of certainty reached, the conclusions of the expert or forensic specialist can be classified: 
Concluding conclusions - consisting of positive or negative answers unequivocally. In other words, these conclusions must make it clear that the sum of the similar features of the studied subject and of the disputed subject is unique, even to other irreparable objects. This is the case for negative categorical conclusions, there must be certainty that the differences between the objects compared are essential and exclude identity.

Conclusions of probability - they must be exclusively the result of elements which restrict the possibility of a categorical idea, that is to say, of a definite, positive or negative conclusion. Such a conclusion should rather be considered as an indication of scientific probity. The claims of a reputed specialist in the field are an expression of this truth.

Conclusions of impossibility - the conclusions of the impossibility of solving the problem are necessary if the determination or rejection of the identity is not possible even with plausibility.

\section{Conclusions}

Being a dynamic process, identification must not be regarded rigidly as the beings and objects that it is studying, constantly changing but still remaining the same. Thus, the forensic identification appears as a process of establishing, through the means and methods of forensic science, the creation factor of the trace based on its defining characteristics, in an individualized and unitary system. This can also be achieved without direct contact, instrumental, tactile, visual with the object to be identified using for this purpose, the recognition according to the essential features when using the previous perceptions of different persons regarding the place, aspect, mode of action of an object, a phenomenon, a person or even an instrument. This method can identify offenders, missing persons, abducted, by comparing their descriptions with the items available.

\section{References}

Bercheşan, V. 2000. Criminal Investigation Methodology. Piteşti: Paralela 45 Publishing House. Bercheşan, V. 2007. Criminal Investigation. Bucharest: Icar Publishing House. Buzatu, N.E. 2013. Forensics. Bucharest: Pro Universitaria Publishing House. Ionescu, L. 2007. Forensics. Bucharest: Pro Universitaria Publishing House. Ionescu, L. and Sandu, D. 2011. Forensic Identification. Bucharest: Scientific Publishing House. Stancu, E. 2010. Forensic Treaty. Bucharest: Universul Juridic Publishing House. Nechita, E.A. 2009. Forensics. Technique and Tactics. $2^{\text {nd }}$ ed. Bucharest: Pro Universitaria Publishing House. 